\title{
ОПЫТ КОМПЛЕКСНОЙ РЕАБИЛИТАЦИИ КОМОРБИДНОГО ПАЦИЕНТА С ОСТРЫМ ИНФАРКТОМ МИОКАРДА НА ФОНЕ САХАРНОГО ДИАБЕТА 2 ТИПА И ОЖИРЕНИЯ
}

\author{
Васильева В.А., Марченкова Л.А.
}

ФГБУ «Национальный медицинский исследовательский центр реабилитации и курортологии» Минздрава России, Москва.

Реабилитация пациентов после перенесенного ОИМ на фоне СД2 в сочетании ожирением представляет сложности и требует персонифицированного подхода. Для таких пациентов следует рассматривать возможность использования индивидуальных реабилитационных программ, включающих немедикаментозные методы на фоне современной фармакотерапии СД.

ЦЕЛЬ: представления клинического случая является описание опыта комплексной реабилитации пациента в раннем периоде ОИМ на фоне СД2 в сочетании с морбидным ожирением с применением современных методов физической терапии и терапии лираглутидом.

ОПИСАНИЕ КЛИНИЧЕСКОГО СЛУЧАЯ: для прохождения 2 этапа медицинской реабилитации поступила пациентка К., 51 года, с диагнозом: Ишемическая болезнь сердца: ОИМ нижней стенки левого желудочка с подъемом ST от 19.12.2019 (8 сутки). Состояние после стентирования правой коронарной артерии от 19.12.2019 г. Гипертоническая болезнь 3 ст, 2 ст, очень высокий риск сердечно - сосудистых осложнений. СД2 (цель $\mathrm{HbA}_{1 c}<7,0 \%$ ). Морбидное ожирение.

Жалобы: выраженную одышку, усиливающиеся при минимальной физической нагрузке, ходьбе, избыточную массу тела, сухость во рту, повышение уровня глюкозы крови до 12 ммоль/л.

Анамнез: ожирение диагностировано после родов в 25 лет. В 2010 году (в 41 год) весила 120 кг, на фоне чего диагностирован СД2. Назначен метформин в дозе 2000 мг/сут., достигнуты целевые значения гликемии и $\mathrm{HbA}_{1 c}$.

Данные обследования: рост 165 см, масса тела (МТ) 152 кг, ИМТ 55,8 кг/м², окружность талии (ОТ) 139 см, бедер (ОБ) 143 см, артериальное давление (АД) 148/98 мм рт.ст. Клинический анализ крови, общий анализ мочи - без патологических изменений. Уровень $\mathrm{HbA}_{1 c}$ 7,6\%, глюкозы натощак 9,1 ммоль/л, общего холестерина (ОХ) 7,4 ммоль/л, триглицеридов (ТГ) 3,08 ммоль/л, липопротеидов низкой плотности (ЛПНП) 4,8 ммоль/л, липопротеидов высокой плотности (ЛПВП) 1,2 ммоль/л. Степень тяжести по шкале реабилитационной маршрутизации 4 балла.

Программа реабилитации: низкокалорийная диета, низкоинтенсивное лазерное воздействие (надвенный лазер по точкам) №10, лечебная физкультура в зале в кардиогруппе №10, занятия на горизонтальном велотренажере №10, спелеокамера №10. Учитывая перенесенный ОИМ, метформин отменен. Начата терапия лираглутидом в начальной дозе 0,6 мг/сут, с последующим ее повышением на 0,6 мг/сут. в неделю до терапевтической дозы 1,8 мг/сут. Нежелательных явлений не отмечено. Выписана через 12 дней для продолжения реабилитации на амбулаторном этапе.

Состояние через 30 дней: удовлетворительное, значительно уменьшилась одышка, возросла толерантность к физическим нагрузкам. МТ 145 кг, ИМТ 53,3 кг/м², ОТ 132 см, ОБ 140 см, АД 124/79 мм рт.ст. Глюкоза 5,3 ммоль/л, ОХ 6,9 ммоль/л, ТГ 3,03 ммоль/л, ЛПНП 4,4 ммоль/л, ЛПВП 1,22 ммоль/л в сыворотке крови. Рекомендовано продолжить диетическую и медикаментозную терапию с увеличением дозы лираглутида до1,8 мг в день.

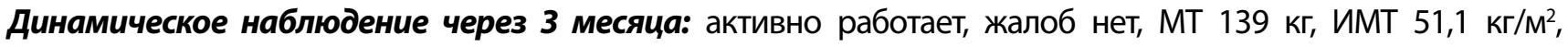
ОТ 128 см, ОБ 132 см, АД 125/78 мм рт.ст. Глюкоза 5,1 ммоль/л, ОХ 5,9 ммоль/л, ТГ 3,01 ммоль/л, ЛПНП 3,52 ммоль/л, ЛПВП 1,36 ммоль/л, $\mathrm{HbA}_{1 с} 6,5 \%$.

ВЫВОД: клинический случай демонстрирует возможности комплексной реабилитации пациентки с ОИМ на фоне СД2 в сочетании с морбидным ожирением с применением методов физической терапии и использованием лираглутида.

КЛЮЧЕВЫЕ СЛОВА: ожирение, острый инфаркт миокарда, сахарный диабет, лираглутид, медицинская реабилитация 